\title{
Filamentous Fungi PKF121 Isolated from Dry Dipterocarp Forest Soil in Northeast Thailand Produces Antimicrobial Agents Active against Methicillin-Resistant Staphylococcus aureus
}

\author{
Phimpha Khowangklang and Nawarat Nantapong*
}

\begin{abstract}
An antimicrobial-producing fungi PKF121 strain was isolated from dry dipterocarp forest soil in Suranaree University of Technology, Nakhon Ratchasima, Thailand. Morphological characteristics of PKF121 showed grayish green color, granular powdery colony and septate hyphae which indicated the genus Penicillium. The species level of PKF121 was determined by the internal transcribed spacer (ITS) sequence analysis. The results of morphological characteristics and ITS sequence analysis, thus, concluded that PKF121 could be classified as $P$. citrinum. Antimicrobial activity analysis showed that PKF121 was active against Staphylococcus aureus, Bacillus subtilis, Bacillus cereus, Candida albicans, Saccharomyces cerevisiae as well as drugresistant strain, methicillin-resistant Staphylococcus aureus (MRSA).
\end{abstract}

Keywords-Antimicrobial, Penicillium, Methicillin-resistant Staphylococcus aureus, MRSA.

\section{INTRODUCTION}

Infectious diseases caused by pathogenic microorganisms including drug-resistant bacteria have been the leading cause of illness and death in human [1]. The major type of drugresistant bacterial strains causing infectious diseases include methicillin-resistant Staphylococcus aureus (MRSA), vancomycin-resistant Staphylococcus aureus (VRSA), vancomycin-resistant Enterococcus (VRE), penicillinresistant Streptococcus pneumonia (PRSP) and multidrugresistant Clostridium difficile (MDR) [2]. Methicillinresistant Staphylococcus aureus (MRSA) is a major cause of hospital-acquired infection. It leads to a higher medical cost, prolonged hospital stay and increased mortality [3]. Thus, there is an increasing need of new and effective drugs for the treatment of infectious diseases. One potential source of novel antibiotics is microorganisms. Many previous studies have shown that antimicrobial-producing microorganisms are widely distributed in natural habitats, especially in soil [4-8]. Soil microorganisms are an important source for bioactive

\footnotetext{
${ }^{1}$ Phimpha Khowangklang and Nawarat Nantapong* are with the School of Preclinical Science, Institute of Science, Suranaree University of Technology, Nakhon Ratchasima, Thailand
}

secondary metabolites such as antimicrobial drugs, anticancer drugs, insecticides and herbicides $[9,10]$. Soil microorganisms that are commonly found to produce antibiotics include actinomycetes (70\%), fungi (20\%) and eubacteria (10\%) [11]. In comparison to other natural sources, microorganisms is highly diverse but narrowly explored. The study based on the estimation of microbial populations has showed that only $1 \%$ of bacteria and $5 \%$ of fungi have been classified. The rest remain unexplored for their antimicrobial activity [12].

Soil fungi play an important role within the soil in relation to nutrient cycling and disease suppression $[13,14]$. Since the 1940s, fungi have been used for the production of antibiotics [11]. Antimicrobial drugs produced by fungi include penicillin, cephalosporin, griseofulvin, fumagillin and fusidic acid [15-17]. Several methods were used for classification and identification of fungi which included colony morphology, cell morphology and ITS sequence analysis. However, the combination of macroscopic characteristics, microscopic characteristics and sequence analysis of ITS enabled an identification of fungi to the genus-species level [18, 19].

It has been reported that $32.1 \%$ of Thailand is covered by various forest habitats [20]. Although, the study of microbial diversity in Thailand have been conducted, an investigation of soil microorganisms including fungi from many part of Thailand remain unexplored. Thus, the present study was focused on the isolation and identification of antimicrobialproducing fungi from forest soil in Nakhon Ratchasima province, Thailand where the study of antimicrobialproducing fungi has never been reported.

\section{MATERIALS AND METHODS}

\section{A. Sample Collection}

Soil Samples were collected from different area in Suranaree University of Technology, Nakhon Ratchasima, Thailand. Soil samples were randomly taken at $10-15 \mathrm{~cm}$ depth from surface. The soil were kept in polypropylene bags and transferred to the laboratory in icebox. 


\section{B. Media and Culture Conditions}

Potato dextrose broth (PDB), potato dextrose agar (PDA) and Muller-Hinton agar (MHA) were purchased from HiMedia, India. Sabouraud dextrose agar (SDA) was prepared by dissolving $10 \mathrm{~g}$ of peptone, $40 \mathrm{~g}$ of glucose and $15 \mathrm{~g}$ of agar in $1 \mathrm{~L}$ of water and adjusted a $\mathrm{pH}$ to 5.6. PDA and PDB medium were used for isolation and cultivation of fungi. Cultivation temperature of fungal strain was $28{ }^{\circ} \mathrm{C}$. MHA and SDA were used for the determination of antimicrobial activity. The incubation temperature for antimicrobial activity test was $37^{\circ} \mathrm{C}$.

\section{Strain of Test Pathogens}

The pathogenic strains used in this study were purchased from Department of Medical Sciences Thailand (DMST) and Thailand Institute of Scientific and Technological Research (TISTR). They were Staphylococcus aureus TISTR1466, methicillin-resistant Staphylococcus aureus DMST20654 (MRSA), Bacillus subtilis TISTR008, Bacillus cereus TISTR687, Candida albicans TISTR5779, Candida tropicalis TISTR5174 and Saccharomyces cerevisiae TISTR5049.

\section{Isolation of Fungi from Soil Sample}

One gram of soil samples was suspended in Erlenmeyer flask containing $99 \mathrm{ml}$ sterile water and incubated at room temperature with shaking condition for $30 \mathrm{~min}$. Soil suspension was serially diluted and spreaded onto PDA plates supplemented with $50 \mathrm{mg} / \mathrm{l}$ chloramphenicol. The plates were incubated at room temperature for 7-14 days. After incubation, the suspected fungal colonies were sub-cultured to PDA plates without antibiotics and used for further study.

\section{E. Determination of Antimicrobial Activity}

The antimicrobial activity of soil isolates were determined by cross-streak method. The fungal isolate was inoculated on MHA or SDA by streaking at one side of a petri dish. MHA medium was used for bacterial sensitivity test while SDA medium was used for yeast sensitivity test. The plates were incubated at $28^{\circ} \mathrm{C}$ for 5 days to allow the organisms to produce and release antimicrobial substance into the agar. After incubation, the test pathogens were streaked perpendicularly to the line of fungal colonies and incubated at $37^{\circ} \mathrm{C}$ for $24-48 \mathrm{~h}$. The zone of inhibition in millimeter against pathogenic strains was measured.

\section{F. The Internal Transcribed Spacer (ITS) Region} Sequencing and Sequence Analysis

Genomics DNA of fungal strain was isolated from cell grown in $10 \mathrm{ml} \mathrm{PDB}$ at $28^{\circ} \mathrm{C}$ with $200 \mathrm{rpm}$ shaking condition for 5 days. Extraction of fungal genomic DNA was performed as described by Al-Samarrai \& Schmid (2000) [21]. The fungal genomic DNA was used as DNA template for PCR amplification of ITS region. The PCR amplification of ITS region was performed by using universal primer, ITS5 (5' -
GGAAGTAAAAGTCGTAACAAGG - 3') and ITS4 (5' TCCTCCGCTTATTGATATGC - 3') [22]. The thermal cycling conditions were as follows: initial denaturation at $95^{\circ} \mathrm{C}$ for 5 min followed by 30 cycles of denaturation at $95^{\circ} \mathrm{C}$ for $30 \mathrm{sec}$, annealing at $50^{\circ} \mathrm{C}$ for $1 \mathrm{~min}$, extension at $72^{\circ} \mathrm{C}$ for $1 \mathrm{~min}$ and final extension at $72^{\circ} \mathrm{C}$ for $7 \mathrm{~min}$. The amplified fragments were purified using NucleoSpin ${ }^{\circledR}$ Gel and PCR clean-up kit (MACHEREY-NAGEL, Germany). The purified PCR product was submitted for DNA sequencing at Macrogen Inc., Korea. The sequence of ITS region was compared with known sequence from NCBI GenBank, database.

\section{RESULTS AND DISCUSSION}

Natural compounds from soil microorganisms are the most important source for the production of bioactive agents used in pharmacy, industry and agriculture [23]. Antimicrobial metabolites play an important role in the treatment of bacterial and fungal infectious diseases [24]. The emergence of antibiotic-resistant bacteria decreases the efficacy of therapeutic drugs [25]. Therefore, it is necessary for the search of the novel effective antibiotics. In this study, we attempted to isolate the antimicrobial-producing fungi from forest soil in Suranaree University of Technology. This area is covered with dry dipterocarp forest. Dry dipterocarp forest soil is less water retention, sandy loam or gravel and low nutrients which could establish slightly extreme condition. Microorganisms live under an extreme condition usually produce the secondary metabolites such as antibiotics and other defensive compounds for their survival [26]. It has been shown that soil from dry dipterocarp forest in Suranaree University of Technology in northeast of Thailand contains a variety of antibiotic-producing actinomycetes [27]. Therefore, the screening and isolation of fungal strain from this area might lead to the discovery of antibiotic drugs to combat pathogenic organisms especially, drug-resistant strain.

\section{A. Isolation and Classification of Soil Fungi PKF121}

In this study we obtained antimicrobial-producing fungal strain, PKF121 from forest soil in Suranaree University of Technology, Thailand. This strain showed antimicrobial activity against test pathogens which were Gram-positive bacteria and yeasts. The identification of PKF121 was based on colony morphology, cell morphology and ITS sequence. The colony of PKF121 appeared grayish green color with a white periphery, granular powdery colony and the reverse side showed pale to yellowish in color on PDA medium (Fig. 1A-1B). PKF121 showed septate hyphae with globose to subglobose conidia and philides flask shaped (Fig. 1C). From these results, it could be suggested that PKF121 might belong to the genus Penicillium. The macroscopic and microscopic characteristics of PKF121 are summarized in Table 1. 

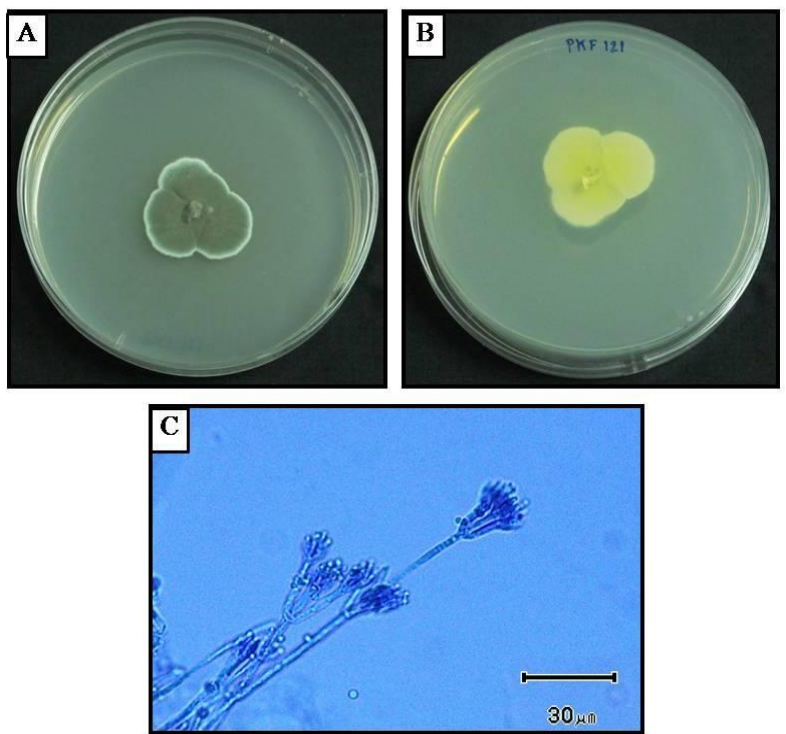

Fig. 1: The colony morphology of fungal isolate PKF121 on PDA medium: (A) obverse; (B) reverse. Cell morphology of PKF121 under light microscope (C)

TABLE 1:

MACROSCOPIC AND MICROSCOPIC MORPHOLOGIES OF PKF121

\begin{tabular}{lc}
\hline Characteristics & Observation \\
\hline Surface texture & Velutinous \\
Colony growth appear & Radially sulcate \\
Color of aerial mycelium & Greyish-turquoise with a white periphery \\
Color of the reverse & Pale yellow \\
Hyphae & Septate hyphae, Smooth-walled \\
Phialides & Flask-shaped \\
Conidia & Globose to sub-globose \\
\hline
\end{tabular}

The internal transcribed spacer (ITS) sequence analysis was used for the identification of PKF121 in the species level. To amplify the ITS region of PKF121, ITS5 and ITS4 primers were used. The sequence of ITS region was blasted and aligned with known species from NCBI GenBank database. The blast result of PKF121 revealed 99\% similarity to Penicillium citrinum strain IFM63148 (Fig. 2). Thus, this strain, could be classified as Penicillium citrinum.

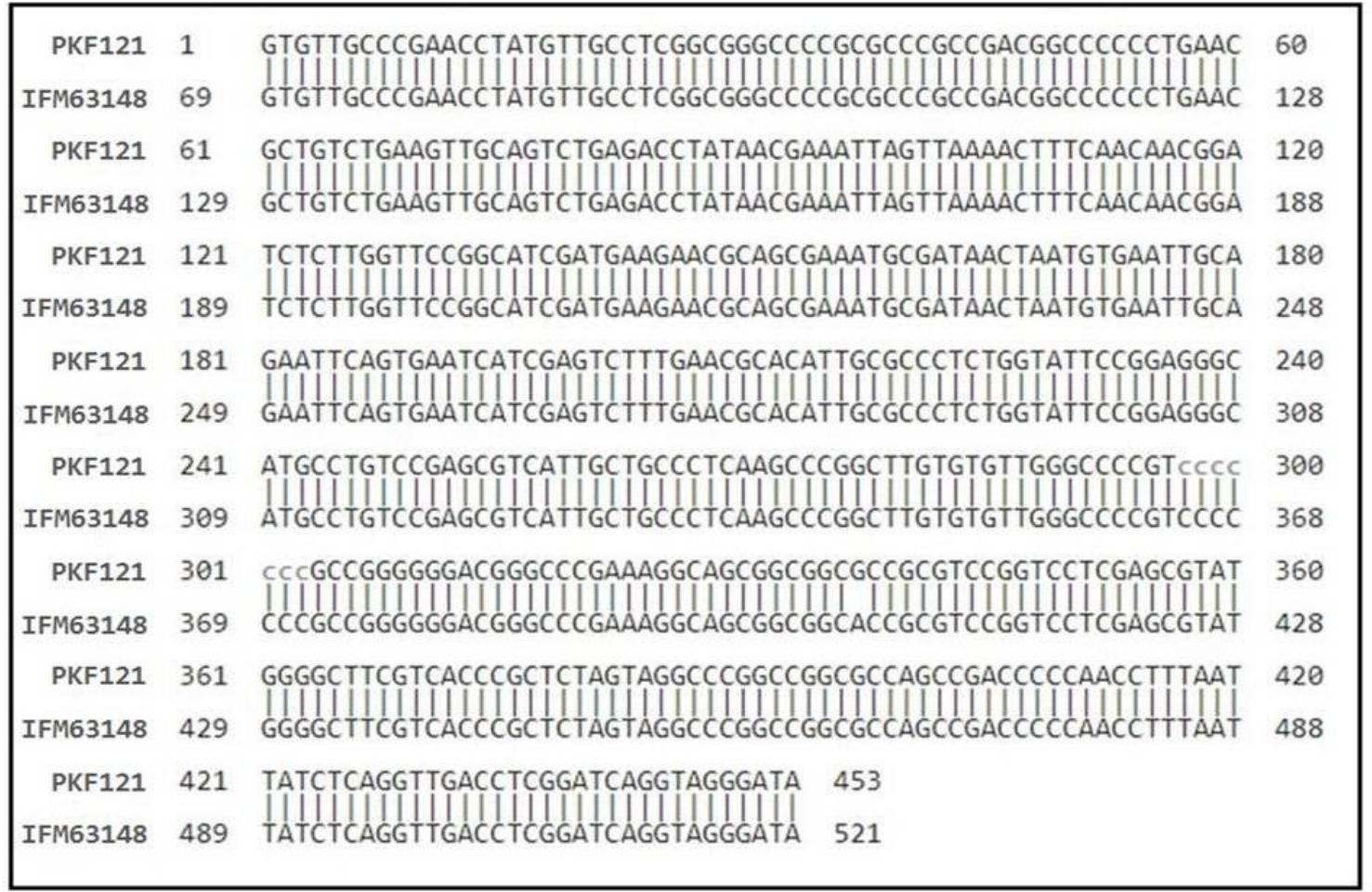

Fig. 2: Alignment sequence between ITS sequence of PKF121 and Penicillium citrinum IFM63148

\section{B. Determination of Antimicrobial Activity of PKF121}

The determination of antimicrobial activity of PKF121 was done by cross-streak method (Fig. 3). The pathogenic strains used in this study were Staphylococcus aureus TISTR1466, methicillin-resistant Staphylococcus aureus DMST20654 (MRSA), Bacillus subtilis TISTR008, Bacillus cereus TISTR687, Candida albicans TISTR5779, Candida tropicalis TISTR5174 and Saccharomyces cerevisiae TISTR5049. The antimicrobial activities of fungal strain PKF121 against test pathogens are shown in Table 2. The results indicated that PKF121 exhibited antibacterial activity toward methicillin-resistant S. aureus, S. aureus, B. subtilis and $B$. cereus. The strain PKF121 showed the highest activity against $B$. subtilis $(42 \mathrm{~mm}$.) followed by $B$. cereus $(35 \mathrm{~mm}$.), MRSA (29 mm.) and $S$. aureus $(22 \mathrm{~mm}$.). The PKF121 also showed antiyeast activity against $C$. albicans $(17 \mathrm{~mm}$.) and $S$. cerevisiae $(8 \mathrm{~mm}$.). Antimicrobial agent produced from PKF121, however, was not active against $C$. tropicalis.

In Thailand, the strains of antimicrobial-producing fungi were isolated from soil collected in Chiang Mai, Khon Kaen, Bangkok and Nakhon Si Thammarat. They were Neosartoya hiratsukae, Neosartorya pseudofischeri, Neosartorya spinosa, Lasiodiplodia theobromae, Sclerotium rolfsii, Phytophthora palmivora, Colletotrichum capsici, Pyricularia grisea, Alternaria sp., Helminthosporium maydis, Rhizoctonia 
solani, Fusarium oxysporum, Colletotrichum gloeosporioides, Trichoderma harzianum, Aspergillus flavus, Trichoderma brevicompactum, Trichoderma atroviride, Fusarium solani and Penicillium sp. [28-31]. However, P. citrinum with antimicrobial and antiyeast activities was reported from Surat Thani province in southern part of Thailand [32]. To our best knowledge, this study provides the first report of antimicrobial producing $P$. citrinum isolate from soil in northeast of Thailand. It should be noted that PKF121 exhibited a relatively high antibacterial activity against MRSA. The study of PKF121 may lead to the development of antimicrobial drug to treat drug-resistant pathogenic strains. Thus, dry dipterocarp forest soil in Suranaree University of Technology has proven to be an attractive source for the search of antimicrobial substances.
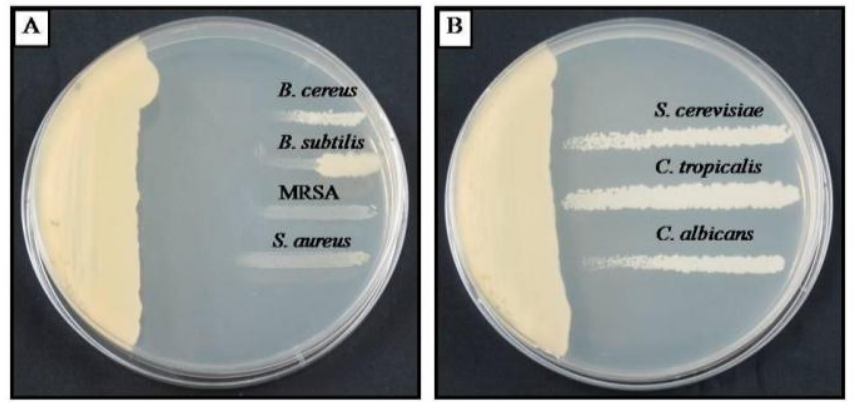

Fig. 3: Antimicrobial activity of fungal strain PKF121 against pathogenic bacteria (A) and yeasts (B) by cross-streak method

TABLE II:

ANTIMICROBIAL ACTIVITY OF PKF121 AGAINST TEST PATHOGENS BY CROSS-STREAK METHOD

\begin{tabular}{lc}
\hline Test pathogens & $\begin{array}{c}\text { Zone of inhibition } \\
(\mathbf{m m})\end{array}$ \\
\hline Gram-positive bacteria & \\
Staphylococcus aureus TISTR1466 & 22 \\
Staphylococcus aureus DMST20654 (MRSA) & 29 \\
Bacillus subtilis TISTR008 & 42 \\
Bacillus cereus TISTR687 & 35 \\
Yeasts & \\
Candida albicans TISTR5779 & 15 \\
Candida tropicalis TISTR5174 & 0 \\
Saccharomyces cerevisiae TISTR5049 & 8 \\
\hline
\end{tabular}

\section{CONCLUSION}

Fungal strain PKF121 was successfully isolated from dry dipterocarp forest soil in Suranaree University of Technology, Thailand. This strain was classified as Penicillium citrinum. It is active against test pathogens including methicillinresistant Staphylococcus aureus. The study of this strain might be further use for the treatment of MRSA infections.

\section{ACKNOWLEDGEMENT}

The authors wish to thank Suranaree University of Technology for research funding through plant genetic conservation project under the Royal initiative of her Royal highness princess Maha Chakri Sirindhorn-Suranaree University of Technology (RSPG-SUT).

\section{REFERENCES}

[1] S. Lihan, Y. K. Choon, N. K. Hua and M. E. Wasli, "Screening for antimicrobial activity of fungi in soil samples collected from kubah national park," International Journal Of Scientific \& Technology Research, vol. 3, pp. 9, Feb 2014.

[2] R. J. Fair and Y. Tor, "Antibiotics and bacterial resistance in the 21st century," Perspectives in Medicinal Chemistry, vol. 6, pp. 25-64, Aug 2014.

https://doi.org/10.4137/PMC.S14459

[3] E. Klein, D. L Smith, and R. Laxminarayan, "Hospitalizations and deaths caused by methicillin-resistant Staphylococcus aureus, United States, 1999-2005," Emerging Infectious Diseases, vol. 13, pp. 1840-1846, Dec 2007.

https://doi.org/10.3201/eid1312.070629

[4] J. O. Falkinham, T. E. Wall, J. R. Tanner, K. Tawaha, F. Q. Alali, C. Li and N. H. Oberlies, "Proliferation of antibiotic-producing bacteria and concomitant antibiotic production as the basis for the antibiotic activity of Jordan's red soils," Applied and Environmental Microbiology, vol. 75, pp. 2735-2741, May 2009. https://doi.org/10.1128/AEM.00104-09

[5] A. Mashoria, H. S. Lovewanshi and B. S Rajawat, "Isolation of antimicrobial producing bacteria from soil samples collected from bhopal region of madhya pradesh, india," International Journal of Current Microbiology and Applied Sciences, vol. 3, pp. 563-569, Dec 2014.

[6] N. Soltani, R. Khavari-Nejad, Y. M. Tabatabaei, S. Shokravi and E. Fernandez-Valiente, "Screening of soil cyanobacteria for antifungal and antibacterial activity," Pharmaceutical Biology, vol. 43, pp. 455-459, Mar 2005.

https://doi.org/10.1080/13880200590963871

[7] O. Tabbene, I. B. Slimene, F. Bouabdallah, M. L. Mangoni, M. C. Urdaci and F. Limam, "Production of anti-methicillin-resistant Staphylococcus activity from Bacillus subtilis sp. strain B38 newly isolated from soil," Applied Biochemistry and Biotechnology, vol. 157, pp. 407-419, Jun 2009.

https://doi.org/10.1007/s12010-008-8277-1

[8] S. Lihan, C. S. Lin, I. Ahmad, F. M. Sinang, N. K. Hua and A. A. Sallehin. (Jan 2014). Antimicrobial producing microbes isolated from soil samples collected from nanga merit forest in sarawak, malaysian borneo. European Journal of Experimental Biology. [online]. 4(1). pp. 494501. Available: http://www.imedpub.com/articles/antimicrobialproducing-microbes-isolated-from-soil-samples-collected-from-nangamerit-forest-in-sarawak-malaysian-borneo.pdf

[9] S. Donadio, P. Monciardini, R. Alduina, P. Mazza, C. Chiocchini, L. Cavaletti, M. Sosio and A. M. Puglia, "Microbial technologies for the discovery of novel bioactive metabolites," Journal of Biotechnology, vol. 99, pp. 187-198, Nov 2002.

https://doi.org/10.1016/S0168-1656(02)00209-2

[10] A. Sharma, N. Kumari and E. Menghani, "Bioactive secondary metabolites: an overview," International Journal of Scientific \& Engineering Research, vol. 5, pp. 1395-1407, Apr 2014.

[11] M. Makut and O. Owolewa, "Antibiotic-producing fungi present in the soil environment of keffi metropolis, nasarawa state, nigeria," Trakia Journal of Sciences, vol. 10, pp. 33-39, 2011.

[12] M. Qadri, S. Johri, B. A. Shah, A. Khajuria, T. Sidiq, S. K. Lattoo, M. Z. Abdin, S. Riyaz-Ul-Hassan, "Identification and bioactive potential of endophytic fungi isolated from selected plants of the western himalayas," SpringerPlus, vol. 2, pp. 14, Dec 2013. https://doi.org/10.1186/2193-1801-2-8

[13] P. Bridge and B. Spooner, "Soil fungi: diversity and detection," Plant and Soil, vol. 232, pp. 147-154, May 2001 https://doi.org/10.1023/A:1010346305799

[14] C. R. Penton, V. Gupta, J. M. Tiedje, S. M. Neate, K. Ophel-Keller, M. Gillings, P. Harvey, A. Pham, D. K. Roget, "Fungal community structure in disease suppressive soils assessed by $28 \mathrm{~S}$ LSU gene sequencing," PLoS One, vol. 9, pp. 12, Apr 2014. https://doi.org/10.1371/journal.pone.0093893

[15] U. Kück, S. Bloemendal and I. Teichert, "Putting fungi to work: harvesting a cornucopia of drugs, toxins, and antibiotics" PLoS Pathogens, vol. 10, pp. 4, Mar 2014. https://doi.org/10.1371/journal.ppat.1003950

[16] C. Hesseltine and J. Ellis, "Antibiotic-producing fungi: current status of nomenclature," Advances in Applied Microbiology; vol. 19, pp. 47-57, 1975.

https://doi.org/10.1016/S0065-2164(08)70422-2 
[17] I. Ullah, N. A. Khan, M. A. Jadoon, H. U. Rehman, H. Khan, M. U. Rehman,A. H.ayat, S. Ali, M. Rehman, M. A. Khan, A. Maqsood and A. Sultana, "Isolation and identification of different Rhizospheres fungi of Mansehra region, Pakistan," Journal of Entomology and Zoology Studies, vol. 5, pp. 437-442, Feb 2017.

[18] T. W. K. Ko, S. L. Stephenson, A. H. Bahkali and K. D. Hyde, "From morphology to molecular biology: can we use sequence data to identify fungal endophytes?," Fungal Diversity, vol. 50, pp. 113-120, Sep 2011. https://doi.org/10.1007/s13225-011-0130-0

[19] R. H. Nilsson, M. Ryberg, K. Abarenkov, E. Sjökvist and E. Kristiansson, "The ITS region as a target for characterization of fungal communities using emerging sequencing technologies," FEMS Microbiology Letters, vol. 296, pp. 97-101, Jul 2009. https://doi.org/10.1111/j.1574-6968.2009.01618.x

[20] The World Bank group, "Forest area (\% of land area)," [online]. Availiable: https://data.worldbank.org/indicator/AG.LND.FRST.ZS, 2015.

[21] T. H. Al-Samarrai and J. Schmid, "A simple method for extraction of fungal genomic DNA," Letters in Applied Microbiology, vol. 30, pp. 536 , Jan 2000. https://doi.org/10.1046/j.1472-765x.2000.00664.x

[22] M. Gardes and T. D. Bruns, "ITS-RFLP matching for identification of fungi" in: J. P. Clapp, Ed. Species diagnostics protocols: PCR and other nucleic acid methods. Totowa, NJ: Humana Press; 1996. pp. 177-86.

[23] S. A. Hassan, E. Hanif and R. R. Zohra, "Isolation and screening of soil bacteria for potential antimicrobial activity," FUUAST Journal of Biology, vol. 4, pp. 217-219, Dec 2014.

[24] M. El-Neketi, W. Ebrahim, W. Lin, S. Gedara, F. Badria, H. E. Saad, D. Lai, P. Proksch, "Alkaloids and polyketides from Penicillium citrinum, an endophyte isolated from the moroccan plant Ceratonia siliqua," Journal of Natural Products, vol. 76, pp. 1099-104, Jun 2013. https://doi.org/10.1021/np4001366

[25] C. L. Ventola, "The antibiotic resistance crisis: part 1: causes and threats," Pharmacy and Therapeutics, vol. 40, pp. 277-83, Apr 2015.

[26] F. Nadeem, M. Oves, H. Qari and I. Ismail, "Red sea microbial diversity for antimicrobial and anticancer agents," Journal of Molecular Biomarker \& Diagnosis, vol. 7, pp. 14, Dec 2015.

[27] P. Chanthasena and N. Nantapong, "Biodiversity of antimicrobialproducing actinomycetes strains isolated from dry dipterocarp forest soil in northeast thailand," Brazilian Archives of Biology and Technology, vol. 59, pp. 11, May 2016. https://doi.org/10.1590/1678-4324-2016150674

[28] S. Poeaim, K. Tongkantom, P. Jabamrung, O. Bo-kaew and M. Soytong, "Isolation, characterization and screening for anticancer and antimicrobial properties of the crude extract from genus Neosartorya," Bioengineering and Bioscience, vol. 4, pp. 71-5, 2016.

[29] W. Sanmanoch, W. Mongkolthanaruk, S. Kanokmedhakul, T. Aimi and S. Boonlue, "Isolation of ascomycetous fungi, Neosartorya spp. and screening for its antibacterial metabolites," Journal of Life Sciences and Technologies, vol. 1, pp. 180-183, Sep 2013. https://doi.org/10.12720/jolst.1.3.180-183

[30] A. Jantasorn, J. Mongon, B. Moungsrimuangdee and T. Oiuphisittraiwat, "In vitro antifungal activity of soil fungi crude extracts isolated from riparian forest against plant pathogenic fungi," Journal of Biopesticides, vol. 9, pp. 119-124, Oct 2016.

[31] S. Wongthong, P. Bangrak, S. Phongpaichit, S. Somrithipol and P. Songkumarn, "Antimicrobial activity of soil fungi from khao nan national park, nakhon si thammarat province, thailand," Journal of Pure and Applied Microbiology, vol. 8, pp. 2999-3010, Aug 2014.

[32] K. Borwornwiriyapan, "Screening of soil fungi from plant genetic conservation project area, rajjaprabha dam, suratthani province which produced antimicrobial substance," M.S. Thesis, Dept. Microbiol., Prince of Songkla Univ., Songkla, Thailand, 2013. 